\title{
Measurement properties of PROMIS short forms for pain and function in total hip arthroplasty patients
}

\author{
Anika Stephan ${ }^{1 *}$ (D) Vincent A. Stadelmann ${ }^{1}$, Michael Leunig ${ }^{2}$ and Franco M. Impellizzeri ${ }^{1,3}$
}

\begin{abstract}
Introduction: While the Patient-Reported Outcomes Measurement Information System (PROMIS) is mainly designed for computer adaptive testing, its static short forms (SF) are used when a paper-pencil format is preferred or item banks are not yet translated into the target language. This study examined the measurement properties of the German PROMIS-SF for pain intensity (PAIN), pain interference (PI) and physical function (PF) in total hip arthroplasty (THA) patients.
\end{abstract}

Methods: SF were collected before and 12 months post-surgery. Higher scores indicate more PAIN, higher PI and better PF. Oxford Hip Score (OHS) was the main reference measure. Six months post-surgery, a subsample completed the SF twice within 14 days to test reliability.

Results: Of 172 eligible patients, 147 consented to participate and received questionnaires; 132 (74 males) returned baseline questionnaires (mean age $65.8 \pm 10.2$ years) and 116, 12-month questionnaires. Forty-five patients provided test-retest data.

Correlations of all SF with OHS were large ( $|r| \geq 0.7$; confidence intervals did not include 0.50). Cronbach's alpha values were: PAIN, 0.86; PI, 0.93; PF, 0.91. Intraclass correlation coefficients were: PAIN, 0.77; PI, 0.81; PF, 0.69. Standard errors of measurement were: PAIN, 3.8; PI, 2.8; PF, 3.6. Smallest detectable change thresholds were: PAIN, 8.8; PI, 6.6; PF, 8.4. Follow-up data showed a ceiling effect (best score) for PAIN (66\%), PI (76\%), and PF (66\%). SF change scores showed large correlations with OHS change scores ( $|r|>0.6)$.

Conclusion: Our results provide some evidence of construct validity, and acceptable reliability and responsiveness of PROMIS-SF for pain and function in THA patients. These SF can thus be considered acceptable for use, although patients' improvement in physical function might be underestimated due to the large follow-up PF score ceiling effects.

\section{Plain English summary}

Measurement qualities of PROMIS instruments are mainly assessed for computer adaptive testing but not for non-adaptive short questionnaires. As these questionnaires are in use, their measurement properties must also be evaluated. Results from computer adaptive testing cannot simply be transferred.

We studied the measurement qualities of the German PROMIS short questionnaires for pain intensity, pain

\footnotetext{
* Correspondence: anika.stephan@kws.ch

'Department of Teaching, Research and Development - Lower Extremities,

Schulthess Clinic, Lengghalde 2, 8008 Zürich, Switzerland

Full list of author information is available at the end of the article
}

\section{Springer Open}

(c) The Author(s). 2021 Open Access This article is licensed under a Creative Commons Attribution 4.0 International License, which permits use, sharing, adaptation, distribution and reproduction in any medium or format, as long as you give appropriate credit to the original author(s) and the source, provide a link to the Creative Commons licence, and indicate if changes were made. The images or other third party material in this article are included in the article's Creative Commons licence, unless indicated otherwise in a credit line to the material. If material is not included in the article's Creative Commons licence and your intended use is not permitted by statutory regulation or exceeds the permitted use, you will need to obtain permission directly from the copyright holder. To view a copy of this licence, visit http://creativecommons.org/licenses/by/4.0/. 
interference and physical function in patients undergoing hip replacement. We wanted to see how these questionnaires perform when compared to the Oxford Hip Score, a standard questionnaire commonly used to test hip-related disability in these patients.

The three questionnaires can be considered acceptable for use in hip replacement patients, but some limitations do exist. Patient improvement in physical function might be underestimated because many patients reach the highest possible score and further improvements cannot be measured. Also, any small but important improvement in physical function cannot be distinguished from measurement error in individual patients.

\section{Introduction}

The Patient Reported Outcomes Measurement Information System (PROMIS ${ }^{\circ}$ ) aims to provide a common health metric for many medical conditions [1]. It is primarily designed for computer adaptive testing (CAT). However, PROMIS static short forms (SF) are also available and in use. PROMIS measurement properties have been investigated in total hip arthroplasty (THA) patients [2-5] but are mostly limited to CAT and focused on single aspects of validity [2], interpretability $[4,5]$ or responsiveness [3]. Conversely, the measurement properties of PROMIS-SF for pain and function in THA patients remain largely undetermined.

German language CAT item banks for pain and function were under development by the German PROMIS group at the time of this study. In future, these PROMIS CAT instruments will be offered by this group for third party use via REDCap (personal communication). Furthermore, not all patients actually prefer electronic over paper forms (according to an internal survey where we found half of our patients reporting their preference for paper questionnaires), and this can influence response rate and adherence. The SF can be easily implemented in clinical registries (especially the shortest versions), while connecting CAT platforms to active registries might initially require additional resources. We decided to use the shortest available SF, which were most feasible for our purposes and minimized respondent and administrative burden (i.e. potential barriers to the collection of patient-reported measures in a clinical setting and registries). Therefore, the aim of the study was to examine the psychometric properties of German PROMIS-SF for pain intensity (PAIN), pain interference (PI) and physical function (PF) in THA patients. Valid

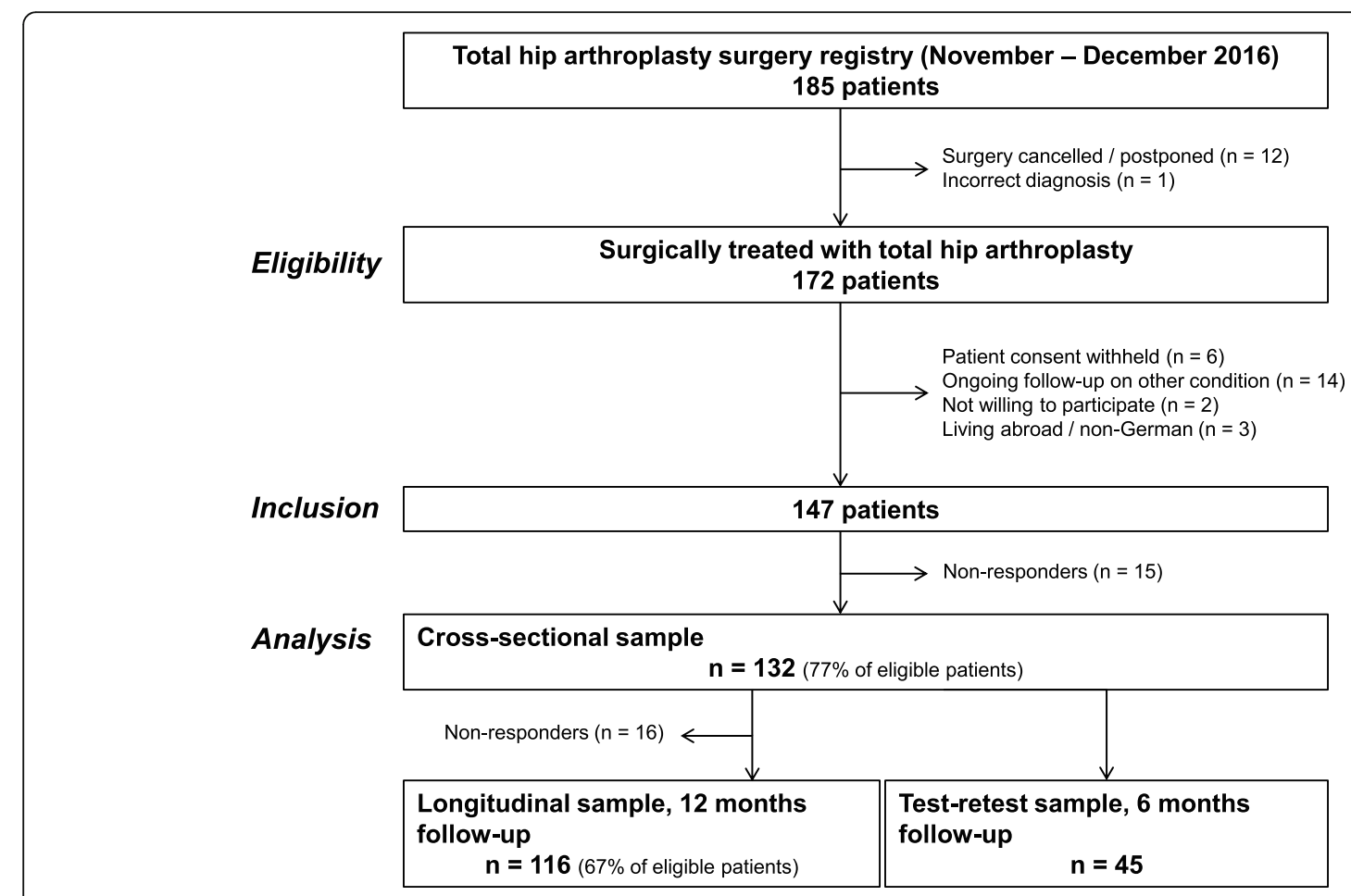

Fig. 1 Flowchart showing patient eligibility and sample sizes for assessing German PROMIS short form measurement properties 
SF would allow the use of PROMIS metrics when CAT cannot be implemented or when SF are deemed more feasible.

\section{Materials and methods}

\section{Study design and questionnaire administration}

This prospective study included consecutive patients of our THA registry from November and December 2016 (Fig. 1). Enrolled patients had to provide consent to use their data for research purposes. Exclusion criteria were living abroad, insufficient knowledge of the German language, cognitive impairment or ongoing follow-up of former surgeries. Ethics approval was obtained. Patientreported outcomes were collected from paper questionnaires administered 1 to 4 weeks before (baseline) and again, from paper questionnaires or, if chosen by the patient, via online survey 12 months after surgery. A subsample of consecutive patients completed questionnaires 6 months after surgery with a retest occurring within 14 days (median: 6 days) for reliability testing until a sample size of 30 was reached. The patients' condition was considered as stable in this period.

\section{Outcome questionnaires}

We investigated PROMIS-SF for PAIN (3 items), PI and PF (each with 4 items) provided by the PROMIS Germany research group. Answers are given on 5-point verbal rating scales. For PAIN, we used the form 3a (v2.0) that assesses pain over a 7-day recall period and current pain [6]. Form 4a (v1.0) defined PI based on the consequences of pain on relevant aspects of one's life over a 7-day recall period $[7,8]$. For PF, we used form 4a (v2.0) $[9,10]$ assessing the current ability to perform various physical activities. Overall scores for PAIN, PI and PF were presented as T-scores; higher scores indicate more PAIN, higher PI and better PF. A score of 50 (10) represents the US general population mean (standard deviation). Scoring was done by using the "HealthMeasures Scoring Service", powered by Assessment Center $^{\mathrm{SM}}$. Missing items were not replaced.

We used the reference Oxford Hip Score (OHS), a condition-specific instrument that assesses constructs encompassing the selected PROMIS domains and 2 single-item questions rating surgical success.

Specifically, we used the cross-culturally adapted and validated German OHS [11, 12]. This 12-item, joint-specific self-administered questionnaire is valid, reliable and responsive for assessing pain and disability in THA patients. Items are answered on 5-point Likert scales extending from 0 to 4 points, where 4 indicates the best outcome. Total scores, calculated by adding all items, range from 0 (worst) to 48 points (best). OHS was shown to have a two-factor structure (pain, function) as well [13].

At 12 months, patients rated their global treatment outcome (GTO): "How much did the operation help your hip problem?" on a 5-point Likert scale ranging from "helped a lot" to "made things worse" [14]. They also defined their state of symptom-specific well-being (SSWB): "If you had to spend the rest of your life with the

Table 1 Baseline patient characteristics and score changes

\begin{tabular}{llll}
\hline Characteristics $^{\text {a }}$ & Cross-sectional $(\boldsymbol{N}=\mathbf{1 3 2})$ & Longitudinal $(\boldsymbol{N}=\mathbf{1 1 6})$ & Test-retest $(\boldsymbol{N}=\mathbf{4 5})$ \\
\hline Age (years) & $65.4(10.9)$ & $65.9(10.2)$ & $68.5(10.9)$ \\
Sex (female) $(\mathrm{n}, \%)$ & $58(43.9)$ & $51(44.0)$ & $16(35.6)$ \\
Height $(\mathrm{cm})$ & $171.1(9.1)$ & $171.5(8.9)$ & $171.5(9.0)$ \\
Weight $(\mathrm{kg})$ & $78.4(14.8)$ & $77.9(14.9)$ & $79.4(13.3)$ \\
Body mass index (kg/m $\left.{ }^{2}\right)$ & $26.7(4.0)$ & $26.4(3.9)$ & $26.9(3.6)$ \\
PROMIS PAIN (T-score) & $65.7(8.7)$ & $65.0(8.8)$ & $64.2(9.6)$ \\
PROMIS PI (T-score) & $64.4(7.0)^{\mathrm{b}}$ & $64.2(7.2)$ & $63.9(8.3)$ \\
PROMIS PF (T-score) & $36.9(5.5)^{\mathrm{b}}$ & $37.3(5.5)$ & $37.2(6.0)$ \\
OHS & $22.1(8.7)^{\mathrm{c}}$ & $22.5(8.8)^{\mathrm{d}}$ & $22.5(9.9)$ \\
PROMIS PAIN (T-score change, 95\% Cl) & & $-20.0(-21.6$ to -18.4$)$ & \\
PROMIS PI (T-score change, 95\% Cl) & $-19.6(-21.1$ to -18.0$)$ & $15.8(14.5$ to 17.0$)$ \\
PROMIS PF (T-score change, 95\% Cl) & & $22.6(21.0$ to 24.3) \\
OHS (score change, 95\% Cl) & & &
\end{tabular}

PROMIS Patient Reported Measurement Outcome Instrumentation System, PAIN Pain intensity, PI Pain interference, PF Physical function, T-score Overall PROMIS score calculated per domain, $\mathrm{OHS}$ Oxford Hip Score, $\mathrm{Cl}$ Confidence interval

${ }^{a}$ Expressed as mean with standard deviation unless otherwise stated

${ }^{b}$ For one case, two of four items were missing, but score calculation was still possible with automated response pattern scoring

${ }^{c}$ For five cases, one to two items were missing and replaced by the mean of all other items to calculate a score

${ }^{\mathrm{d} O n e}$ item was missing for one case, which was replaced by the mean of all other items to calculate a score 
symptoms you have right now, how would you feel about it?" on a 5-point Likert scale ranging from "very satisfied" to "very dissatisfied" [15].

\section{Evaluation of measurement properties}

Construct validity was assessed using scale-specific hypothesis testing and considered good if at least $75 \%$ of the hypotheses were confirmed. We tested correlations with OHS total score and OHS pain and function subscales at baseline and 12 months, and SSWB at 12 months. All correlations were expected to be large (confidence intervals $\geq 0.5$ ), and specific correlations were expected to be negative for PAIN and PI with OHS and for PF with SSWB and positive for PAIN and PI with SSWB and PF with OHS.

Internal consistency was calculated using Cronbach's alpha with values between 0.70 and 0.95 indicating appropriate internal consistency [16]. Testretest reliability was assessed with the intraclass correlation coefficient (ICC) from a single measurement, absolute agreement, 2-way mixed-effects model; an ICC (confidence interval) $\geq 0.7$ was considered acceptable [16]. Agreement was assessed using the standard error of measurement $\left(\mathrm{SEM}_{\mathrm{agr}}=\sqrt{ }(\right.$ variance due to systematic differences between measurements + residual variance)). The effect size based on $\mathrm{SEM}_{\text {agr }}$ was calculated from the mean change score. The smallest detectable change (SDC) for individuals that can be considered above the measurement error with a $90 \%$ confidence level was calculated as $\operatorname{SDC} 90=1.65 * \sqrt{ } 2$ * SEM agr [17].

Responsiveness defines the ability of a questionnaire to detect clinically important changes over time. Longitudinal validity can be considered a measure of responsiveness and is examined by inspecting the correlation between change scores of the instrument under validation and the reference instrument. We expected negative correlations between change scores of PAIN, PI and OHS, and positive correlations between change scores of PF and OHS, each in the order of $|\mathrm{r}|$ (confidence intervals) $\geq 0.5$. The smallest effect size of interest was defined as a Cohen's $d \geq 1.5$ for the decrease in PI and increase in PF based on other studies [3, 18]. Responsiveness was considered sufficient if at least $75 \%$ of the hypotheses were confirmed.

Floor and ceiling effects were considered acceptable if percentages were below 15\%. To determine the individual-level minimal important change (MIC), we used linear regression with the OHS change scores and reported MIC for OHS in THA patients [19].

Analyses were performed using Stata Statistical Software Release 15 (StataCorp LP, TX, USA).

\section{Results}

Table 1 presents the baseline demographics with pain and function status. Age range was 32 to 93 years with a median of 66.8 years. Most surgeries were primary THA $(92 \%)$ and $8 \%$ of patients underwent THA revisions.

\section{Construct validity}

Scale-specific hypothesis testing for validity resulted in $100 \%$ confirmed hypotheses for PAIN, $89 \%$ for PI and $78 \%$ for PF (Table 2).

Table 2 Correlations between PROMIS scales and OHS and SSWB

\begin{tabular}{|c|c|c|}
\hline & Correlation with $\mathrm{OHS}^{\mathrm{a}, \mathrm{b}}$ & Correlation with SSWB ${ }^{a, c}$ \\
\hline \multicolumn{3}{|l|}{ PROMIS PAIN } \\
\hline \multirow[t]{2}{*}{ Baseline } & $-0.83(-0.88$ to -0.77$)$ & - \\
\hline & $-0.84(-0.88 \text { to }-0.78)^{\mathrm{e}}$ & \\
\hline \multirow[t]{2}{*}{12 months } & $-0.84(-0.89$ to -0.78$)$ & 0.69 (0.58 to 0.77$)$ \\
\hline & $-0.86(-0.90 \text { to }-0.80)^{\mathrm{e}}$ & \\
\hline Change & $-0.81(-0.87 \text { to }-0.74)^{d}$ & - \\
\hline \multicolumn{3}{|l|}{ PROMIS PI } \\
\hline \multirow[t]{2}{*}{ Baseline } & $-0.84(-0.89$ to -0.78$)$ & - \\
\hline & $-0.78(-0.81 \text { to }-0.71)^{\mathrm{e}}$ & \\
\hline \multirow[t]{2}{*}{12 months } & $-0.84(-0.88$ to -0.77$)$ & $0.66(0.55 \text { to } 0.76)^{g}$ \\
\hline & $-0.81(-0.86 \text { to }-0.74)^{\mathrm{e}}$ & \\
\hline Change & $-0.76(-0.82 \text { to }-0.67)^{d}$ & - \\
\hline \multicolumn{3}{|l|}{ PROMIS PF } \\
\hline \multirow[t]{2}{*}{ Baseline } & $0.82(0.75$ to 0.87$)$ & - \\
\hline & $0.80(0.73 \text { to } 0.86)^{f}$ & \\
\hline \multirow[t]{2}{*}{12 months } & 0.79 (0.70 to 0.85$)$ & $-0.53(-0.65 \text { to }-0.38)^{\mathrm{h}}$ \\
\hline & $0.80(0.72 \text { to } 0.86)^{f}$ & \\
\hline Change & $0.72(0.63 \text { to } 0.80)^{d}$ & - \\
\hline \multicolumn{3}{|l|}{$\mathrm{OHS}$} \\
\hline 12 months & - & $-0.65(-0.74$ to -0.53$)$ \\
\hline Change & - & - \\
\hline
\end{tabular}

PROMIS Patient Reported Measurement Outcome Instrumentation System, OHS Oxford Hip Score, SSWB Symptom-specific well-being, PAIN Pain intensity, PI Pain interference, PF Physical function

${ }^{a}$ Correlation coefficients are shown for the total sample. Analysis was done for male and female subsamples as well. If not indicated $\left({ }^{9}\right)$, correlation coefficients for male and female subsamples are above the required threshold (confidence intervals do not include 0.5 )

${ }^{\mathrm{b}}$ Pearson's correlation coefficient $(r)$

'Spearman's rank correlation coefficient $\left(r_{s}\right)$

${ }^{\mathrm{d}}$ Correlation OHS change score

${ }^{\text {e}}$ Coefficients for OHS pain subscale

${ }^{f}$ Coefficients for OHS function subscale

gLarge correlation was not confirmed for the male subsample (absolute values of the confidence interval limits were required to be $\geq 0.5$ )

${ }^{h}$ Large correlation was not confirmed for the total sample and male subsample (absolute values of the confidence interval limits were required to be $\geq 0.5$ ) 


\section{Reliability}

Cronbach's alpha ranged between 0.7 and 0.95 . ICC confidence intervals were $\geq 0.7$ for PAIN and PI, but not for PF (Table 3). PAIN showed the highest SEM agr $_{\text {and }}$ SDC90, whereas PI had the lowest. The effect size based on $\mathrm{SEM}_{\text {agr }}$ was smallest for PF, and smaller than OHS for all three SF.

\section{Responsiveness}

Hypothesis testing for responsiveness resulted in confirmation of all hypotheses about correlations between SF and OHS change scores; SF change score scatter plots are shown in Fig. 2. We observed a cluster of cases with a PI change score of -34 , which represents patients that changed from the worst to best PI score (14 of 116 cases). Cohen's $d$ (95\% confidence interval) values were: PAIN, $-2.9(-3.3$ to -2.5$)$; PI, $-3.0(-3.4$ to -2.6$)$; PF, 2.7 (2.4 to 3.1 ).

We found ceiling effects (best score) for PAIN (66\%), PI (76\%), and PF (66\%) after surgery. MICs were: PAIN, - 10; PI, - 8.8; PF, 7.2 (T-score change).

\section{Discussion}

Our results suggest that the construct validity of PROMIS-SF is acceptable in THA patients. The SF have good internal consistency, test-retest reliability and responsiveness. For PAIN and PI, MICs were larger than the corresponding SDC90 values. Some measurement property limitations were nevertheless detected.

For PF, MIC was smaller than SDC90 meaning that clinically relevant change could not be distinguished from measurement error on the individual level. Compared to OHS, all SF show $40 \%$ to $60 \%$ smaller effect sizes based on $\mathrm{SEM}_{\mathrm{agr}}$, which means that the jointspecific OHS allows more detailed grading of patient recovery than the PROMIS-SF scales.

The high proportion of patients with best possible scores of PI and PAIN after surgery may be not critical. These scales represent unipolar constructs where the complete absence of pain or pain interference makes it difficult (yet likely less relevant) to differentiate them any further. Nevertheless, researchers should be careful in interpreting PF after surgery because of ceiling effects. This problem may be resolved by using PF CAT without substantially increasing respondent burden [20,21]. Although confirmation of this aspect is warranted, we think it is unlikely that longer SF (i.e. $6 \mathrm{~b}, 8 \mathrm{~b}, 20 \mathrm{a}$ or $12 \mathrm{a}$ for people who can walk) will impact the ceiling effect because their maximum $\mathrm{T}$-score is only slightly higher (59 to 66) than that of the 4-item SF $(57)[9,21]$. There was also $12 \%$ of patients who went from the worst possible to best possible PI score from baseline to followup, which can be critical if a more detailed grading of recovery is desired.

\section{Limitations}

THA is typically associated with very high patient satisfaction. Consequently, we did not have patients in the "poor outcome" category upon dichotomisation of the GTO, and MIC could not be calculated with an anchorbased standard method using the receiver operating characteristics curve. For this reason, we adopted an alternative indirect approach using linear regression from the OHS MIC calculated in a much larger study with 82 , 415 THA patients [19].

Only $77 \%$ of eligible patients responded at baseline and $67 \%$ at follow-up. From our internal registry qualitycontrol procedures, we know that "lack of time" is the most common reason for not responding. From followup non-responders, less than $3 \%$ refused to cooperate because they were dissatisfied with their treatment, which suggests that there was no major selection bias.

Unidimensionality of the SF scale structure was not assessed, due to existing reports and guidelines of the development of PROMIS item banks [1, 22, 23]. The unidimensionality of the PF and PI item banks has been reported previously $[8,24]$.

\section{Conclusion}

Our results provide some evidence of construct validity, and acceptable reliability and responsiveness of

Table 3 Reliability, agreement and smallest detectable change

\begin{tabular}{|c|c|c|c|c|c|}
\hline & Cronbach's $a^{a}$ & $I C C^{a}$ & $\mathrm{SEM}_{\mathrm{agr}}$ & SDC90 & $\frac{\text { mean change score }}{\mathrm{SEM}_{\mathrm{agr}}}$ \\
\hline PROMIS PAIN & 0.86 (0.82 to 0.90$)$ & 0.77 (0.60 to 0.87$)$ & 3.75 & 8.75 & 6.4 \\
\hline PROMIS PI & 0.93 (0.90 to 0.94) & 0.81 (0.67 to 0.89 ) & 2.83 & 6.61 & 6.9 \\
\hline PROMIS PF & 0.91 (0.88 to 0.93$)$ & 0.69 (0.50 to 0.81$)$ & 3.60 & 8.40 & 4.4 \\
\hline $\mathrm{OHS}$ & - & - & 2.08 & $4.85^{b}$ & 10.9 \\
\hline
\end{tabular}

ICC Intraclass correlation coefficient, SEM agr Agreement assessed using standard error of measurement, SDC90 Smallest detectable change for individuals that can be considered above the measurement error with a $90 \%$ confidence level, PROMIS Patient Reported Measurement Outcome Instrumentation System, PAIN Pain intensity, PI Pain interference, PF Physical function, OHS Oxford Hip Score

${ }^{2} 95 \%$ confidence interval in parentheses

beard et al. (2015) [19] 


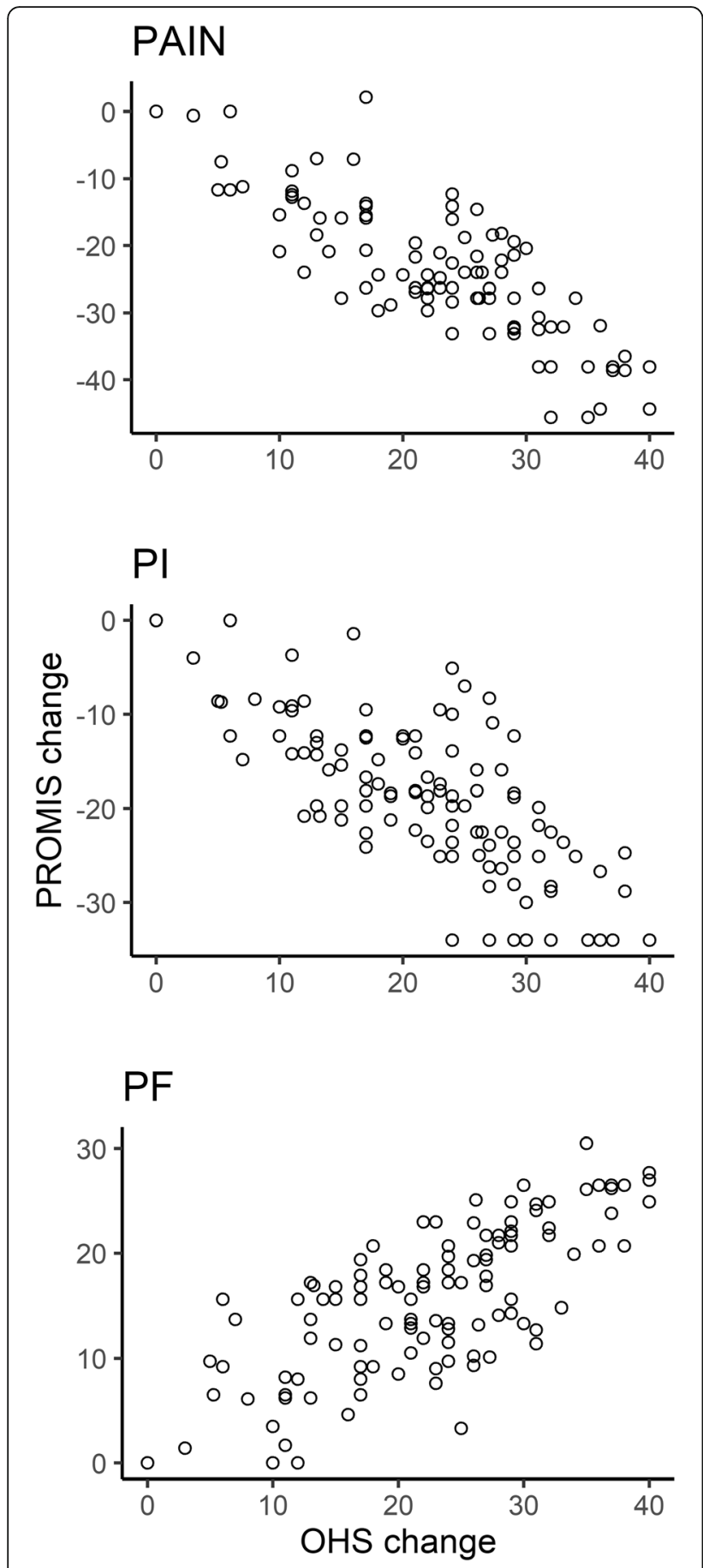

Fig. 2 Responsiveness plots

PROMIS-SF for pain and function in THA patients. The SF can thus be considered as acceptable as another common static instrument (i.e. OHS) for use in these patients, although improvement in PF might be underestimated due to the large follow-up PF score ceiling effects.

\section{Abbreviations}

CAT: Computer adaptive testing; GTO: Global treatment outcome; ICC: Intraclass correlation coefficient; MIC: Minimal important change; OHS: Oxford Hip Score; PAIN: Pain intensity; PF: Physical function; PI: Pain interference; PROMIS: Patient Reported Outcomes Measurement Information System; REDCap: Research electronic data capture; SDC: Smallest detectable change; SEMagr: Agreement assessed using the standard error of measurement; SF: Short forms; SSWB: Symptom-specific well-being; THA: Total hip arthroplasty

\section{Acknowledgements}

The authors thank Melissa Wilhelmi (Schulthess Clinic) for manuscript editing as well as the Lower Extremities Research and Development team members Selina Nauer, Myrta Rüegger, Marissa Jauslin and Sandra Alvarez as well as former members for their valuable assistance with the data collection.

\section{Authors' contributions}

All authors have been actively involved in the planning and enactment of the study, and also assisted with the preparation of the submitted article. Anika Stephan: study design; data analysis and interpretation; writing paper and proofing final manuscript. Vincent Stadelmann: data analysis; proofing final manuscript. Michael Leunig: surgical expertise; proofing final manuscript. Franco Impellizzeri: study conception and design; proofing final manuscript. The author(s) read and approved the final manuscript.

\section{Funding}

Not applicable.

\section{Availability of data and materials}

The datasets used and/or analysed during the current study are available from the corresponding author on reasonable request.

\section{Declarations}

\section{Ethics approval and consent to participate}

The Cantonal Ethics Commission of Zurich approved the reuse of routinely collected data for this study (no. 2015-0258). Patients gave their consent to the use of their data for such purposes. All procedures performed in studies involving human participants were in accordance with the ethical standards of the institutional and/or national research committee and with the 1964 Helsinki Declaration and its later amendments or comparable ethical standards.

\section{Consent for publication}

Not applicable.

\section{Competing interests}

The authors declare that they have no competing interests.

\section{Author details}

${ }^{1}$ Department of Teaching, Research and Development - Lower Extremities, Schulthess Clinic, Lengghalde 2, 8008 Zürich, Switzerland. ${ }^{2}$ Hip Surgery, Schulthess Clinic, Lengghalde 2, 8008 Zürich, Switzerland. ${ }^{3}$ Faculty of Health, University of Technology Sydney, PO Box 123, Broadway, Ultimo, NSW 2007, Australia.

Received: 20 January 2021 Accepted: 30 April 2021

Published online: 30 May 2021

\section{References}

1. Cella, D., Riley, W., Stone, A., Rothrock, N., Reeve, B., Yount, S., ... PROMIS Cooperative Group (2010). The patient-reported outcomes measurement information system (PROMIS) developed and tested its first wave of adult self-reported health outcome item banks: 2005-2008. Journal of Clinical Epidemiology, 63(11), 1179-1194. https://doi.org/10.1016/j.jclinepi.2010.04. 011.

2. Padilla, J. A., Rudy, H. L., Gabor, J. A., Friedlander, S., Iorio, R., Karia, R. J., \& Slover, J. D. (2019). Relationship between the patient-reported outcome measurement information system and traditional patient-reported outcomes for osteoarthritis. The Journal of Arthroplasty, 34(2), 265-272. https://doi.org/10.1016/j.arth.2018.10.012. 
3. Lawrie, C. M., Abu-Amer, W., Barrack, R. L., \& Clohisy, J. C. (2020). Is the patient-reported outcome measurement information system feasible in bundled payment for care improvement in total hip arthroplasty patients? The Journal of Arthroplasty, 35(5), 1179-1185. https://doi.org/10.1016/j.arth.2 019.12.021.

4. Stiegel, K. R., Lash, J. G., Peace, A. J., Coleman, M. M., Harrington, M. A., \& Cahill, C. W. (2019). Early experience and results using patient-reported outcomes measurement information system scores in primary total hip and knee arthroplasty. The Journal of Arthroplasty, 34(10), 2313-2318. https://doi. org/10.1016/j.arth.2019.05.044.

5. Hung, M., Bounsanga, J., Voss, M. W., \& Saltzman, C. L. (2018). Establishing minimum clinically important difference values for the patient-reported outcomes measurement information system physical function, hip disability and osteoarthritis outcome score for joint reconstruction, and knee injury and osteoarthritis outcome score for joint reconstruction in orthopaedics. World Journal of Orthopedics, 9(3), 41-49. https://doi.org/10.5312/wjo.v9.i3.41.

6. Pain Intensity. A brief guide to the PROMIS ${ }^{\oplus}$ Pain Intensity instruments. 2020. http://www.healthmeasures.net/administrator/components/com_ instruments/uploads/PROMIS\%20Pain\%20Intensity\%20Scoring\%20Manual. pdf. Accessed June 2020.

7. Pain Interference. A brief guide to the PROMIS@ Pain Interference instruments. 2020. http://www.healthmeasures.net/administrator/ components/com_instruments/uploads/PROMIS\%20Pain\%20Interference\%2 OScoring\%20Manual.pdf. Accessed June 2020.

8. Amtmann, D., Cook, K. F., Jensen, M. P., Chen, W. H., Choi, S., Revicki, D., ... Lai, J. S. (2010). Development of a PROMIS item bank to measure pain interference. Pain, 150(1), 173-182. https://doi.org/10.1016/j.pain.2010.04.025

9. Physical Function. A brief guide to the PROMIS ${ }^{\oplus}$ Physical Function instruments. 2020. http://www.healthmeasures.net/administrator/ components/com_instruments/uploads/PROMIS\%20Physical\%20Function\%2 OScoring\%20Manual.pdf. Accessed June 2020.

10. Rose, M., Bjorner, J. B., Gandek, B., Bruce, B., Fries, J. F., \& Ware Jr., J. E. (2014). The PROMIS Physical Function item bank was calibrated to a standardized metric and shown to improve measurement efficiency. Journal of Clinical Epidemiology, 67(5), 516-526. https://doi.org/10.1016/j.jclinepi.2013.10.024.

11. Naal, F. D., Impellizzeri, F. M., Miozzari, H. H., Mannion, A. F., \& Leunig, M. (2011). The German hip outcome score: Validation in patients undergoing surgical treatment for femoroacetabular impingement. Arthroscopy, 27(3), 339-345. https://doi.org/10.1016/j.arthro.2010.07.021.

12. Dawson, J., Fitzpatrick, R., Carr, A., \& Murray, D. (1996). Questionnaire on the perceptions of patients about total hip replacement. The Journal of Bone and Joint Surgery. British Volume, 78(2), 185-190.

13. Harris, K. K., Price, A. J., Beard, D. J., Fitzpatrick, R., Jenkinson, C., \& Dawson, J. (2014). Can pain and function be distinguished in the Oxford hip score in a meaningful way? Bone \& Joint Research, 3(11), 305-309. https://doi.org/10.13 02/2046-3758.311.2000313.

14. Mannion, A. F., Junge, A., Grob, D., Dvorak, J., \& Fairbank, J. C. (2006) Development of a German version of the Oswestry disability index. Part 2: Sensitivity to change after spinal surgery. European Spine Journal, 15(1), 6673. https://doi.org/10.1007/s00586-004-0816-z.

15. Mannion, A. F., Elfering, A., Staerkle, R., Junge, A., Grob, D., Semmer, N. K., .. Boos, N. (2005). Outcome assessment in low back pain: How low can you go? European Spine Journal, 14(10), 1014-1026. https://doi.org/10.1007/ s00586-005-0911-9.

16. Terwee, C. B., Bot, S. D., de Boer, M. R., van der Windt, D. A., Knol, D. L. Dekker, J., et al. (2007). Quality criteria were proposed for measurement properties of health status questionnaires. Journal of Clinical Epidemiology, 60(1), 34-42. https://doi.org/10.1016/j.jclinepi.2006.03.012.

17. de Vet, H. C. W., Terwee, C. B., Mokkink, L. B., \& Knol, D. L. (2011). Measurement in medicine. Cambridge: Cambridge University Press. https:// doi.org/10.1017/CBO9780511996214.

18. Quinzi, D. A., Childs, S., Kuhns, B., Balkissoon, R., Drinkwater, C., \& Ginnetti, J. (2020). The impact of total hip arthroplasty surgical approach on patientreported outcomes measurement information system computer adaptive tests of physical function and pain Interference. The Journal of Arthroplasty, 35(10), 2899-2903. https://doi.org/10.1016/j.arth.2020.05.006.

19. Beard, D. J., Harris, K., Dawson, J., Doll, H., Murray, D. W., Carr, A. J., \& Price, A. J. (2015). Meaningful changes for the Oxford hip and knee scores after joint replacement surgery. Journal of Clinical Epidemiology, 68(1), 73-79. https:// doi.org/10.1016/j.jclinepi.2014.08.009.
20. Kollmorgen, R. C., Hutyra, C. A., Green, C., Lewis, B., Olson, S. A., \& Mather 3rd., R. C. (2019). Relationship between PROMIS computer adaptive tests and legacy hip measures among patients presenting to a tertiary care hip preservation center. The American Journal of Sports Medicine, 47(4), 876-884. https://doi.org/10.1177/0363546518825252.

21. Segawa, E., Schalet, B., \& Cella, D. (2020). A comparison of computer adaptive tests (CATs) and short forms in terms of accuracy and number of items administrated using PROMIS profile. Quality of Life Research, 29(1), 213-221. https://doi.org/10.1007/s11136-019-02312-8.

22. Reeve, B. B., Hays, R. D., Bjoerner, J. B., Cook, K. F., Crane, P. K., Teresi, J. A., et al. (2007). Psychometric evaluation and calibration of health-related quality of life item banks: Plans for the Patient-Reported Outcomes Measurement Information System (PROMIS). Medical Care, 45(5 Suppl. 1), S22-S31.

23. Health Nlo (2013). PROMIS ${ }^{\oplus}$ instrument development and validation scientific standards version 2.0 (revised May 2013), (p. 72).

24. Liegl, G., Rose, M., Correia, H., Fischer, H. F., Kanlidere, S., Mierke, A., et al. (2017). An initial psychometric evaluation of the German PROMIS v1.2 Physical Function item bank in patients with a wide range of health conditions. Clinical Rehabilitation, 269215517714297. https://doi.org/10.1177/ 0269215517714297.

\section{Publisher's Note}

Springer Nature remains neutral with regard to jurisdictional claims in published maps and institutional affiliations.

\section{Submit your manuscript to a SpringerOpen ${ }^{\circ}$ journal and benefit from:}

- Convenient online submission

- Rigorous peer review

- Open access: articles freely available online

High visibility within the field

- Retaining the copyright to your article

Submit your next manuscript at $\boldsymbol{\nabla}$ springeropen.com 